\title{
Assessment of Fractional Collection Efficiency in Louvered Inertial Particle Classifiers
}

\author{
T. R. Blake
}

Mechanical and Industrial Engineering Department, University of Massachusetts, Amherst MA, 01003 USA blake@ecs.umass.edu 


\section{Nomenclature}

$A_{r}-$ Area (height) for inlet flow/area (height) for minor flow

$\mathrm{b}$ - Perpendicular distance or space between adjacent louvers

c - Louver chord length

$\mathrm{C}\left(\mathrm{P}, \mathrm{T}, \mathrm{D}_{\mathrm{p}}\right)-$ Slip correction

$\mathrm{C}_{\mathrm{p}}=\Delta \mathrm{P} /\left[\rho \mathrm{V}^{2} / 2\right]$ - Pressure loss coefficient for the classifier

$\mathrm{D}_{\mathrm{p}}$ - Particle diameter

$\mathrm{K}=\mathrm{b} \sin (\alpha) / \mathrm{Y} \sin (\beta)$ - Roughness of the array of louvers

$\mathrm{P}$ - Gas pressure

$\mathrm{q}_{\mathrm{o}}$ - Gas volume flow rate, per unit depth, at ambient pressure and temperature

$\mathrm{T}-$ Gas temperature

$\operatorname{Re}=\rho \mathrm{VY} / \mu-$ Reynolds number for flow past louvers

$\mathrm{St}=\rho_{\mathrm{p}}\left(\mathrm{D}_{\mathrm{p}}{ }^{2}\right) \mathrm{VC}\left(\mathrm{P}, \mathrm{T}, \mathrm{D}_{\mathrm{p}}\right) / 18 \mathrm{~b} \mu-$ Stokes number

$\mathrm{V}-$ Axial gas velocity of classifier

$(\mathrm{x}, \mathrm{y})$ - coordinates in axial and vertical directions of classifier

$\mathrm{Y}$ - height from centerline of rectilinear inlet

$\alpha$ - Face angle of the array (line of leading edges) relative to axis of classifier

$\beta$ - Angle between the louver and the face of the array of louvers

$\gamma=\alpha+\beta-$ Angle between the louver and axis of classifier

$\Delta \mathrm{P}$ - Pressure loss of classifier

$\eta$ - Fractional collection efficiency of classifier $(\mathrm{H}-$ the conditional mean of $\eta)$

$\mu=\mu(\mathrm{T})$ - Gas dynamic viscosity

$\rho=\mathrm{P} / \mathrm{RT}-$ Gas density, $\mathrm{R}=\mathrm{Ru} / \mathrm{W}$

$\rho_{\mathrm{p}}$ - Particle density

$\overline{\log (\mathrm{K})}$, etc- Mean value of independent variable for data set

$\log (\mathrm{K})-\overline{\log (\mathrm{K})}=[\log (\mathrm{K})]_{\mathrm{C}}$, etc - Centered independent variable 


\section{Introduction}

This study reexamines the literature data on performance of louvered inertial classifiers, which incorporate a converging array of blades to intercept the inlet particle laden gas and separate it into major and minor flows. The larger particles follow the minor or "blow down" flow for collection [1].

These classifiers can provide high volumetric flow rates with low pressure loss in a compact configuration $[4,11]$. They have been widely used in removing particles on the order of $10 \mu \mathrm{m}$ or larger from the exhaust of power plants and chemical reactors [7, 11 - 13], and from inlet air flow to engines and gas turbines [4 - 6, 14]. However a small and disparate experimental base hinders their broader application.

A correlation of particle fractional collection efficiency is developed which offers an interpretation of the data, providing a basis for classifier design, and enabling a comparison with other classifiers. The emphasis is on data for rectilinear classifier geometries with flat plate louvers as in [1 - 5]. However, the correlation should be useful in assessing variations on rectilinear geometries such as that of [e.g. 6 - 7], and of cylindrical geometries [e.g. 8 -10].

The correlation is based on the limited data from [1 - 3] and so it is presented as a preliminary framework for interpreting rectilinear louvered inertial classifiers that might encourage further experimental study. It mimics the analyses and more robust data bases for cyclone classifiers [15 - 17] and conventional and virtual impactors [18 - 20]. Analogous to such devices, the fractional collection efficiency of rectilinear louvered classifiers $\eta$, is strongly influenced by a Stokes number St; the correlation shows that $\eta \sim$ $\log \left(\mathrm{St}^{1 / 2}\right)$ for $\eta$ near 0.5 with $0.2<\mathrm{St}^{1 / 2}<1.0$. As in [1 - 3] the spacing between the louvers $\mathrm{b}$, is the physical length scale in St. Other geometric variables affect fractional collection efficiency and the correlation permits a quantitative assessment of that geometry on $\eta$. The respective influences of orientation, chord and spacing of the louvers and the converging profile of the louver array are examined. For example, the face angle of the louver array $\alpha$ is significant. The correlation shows that when $\alpha$ is approximately $4^{\circ}$ the fractional collection efficiency for any $\mathrm{St}^{1 / 2}$ is a maximum, which agrees with the observations of [2], but here the data of other investigators is included. Thus the selective classification of a particle of size $\mathrm{D}_{\mathrm{p} 50}$, in a louver array with a face angle greater than $4^{\mathrm{o}}$, requires a larger $\mathrm{St}_{50}{ }^{1 / 2}$.

Additional experiments can be assessed within the context of the correlation and in turn applied to modify it. The design of a new louvered classifier can be based on $\mathrm{St}_{50}$ and $\mathrm{D}_{\mathrm{p} 50}$ from the correlation. 


\section{Methods, hydrodynamic considerations, and non-dimensional variables}

Multiple linear regression analysis [21,22] is used for correlating the fractional collection efficiency data of Hiyoshi, et al [1], Ushiki, et al [2] and Okada, et al [3]. This correlation is based on non-dimensional variables that define the geometry and hydrodynamic environment.

The rectilinear classifier of [2] is a single array of flat plate louvers opposite a solid wall, and is compatible with those of [1] and [3] for symmetric arrays of louvers divided by a center plate. In Figure 1 a schematic of three of nine louvers, applicable to a geometry in [2], shows the salient geometric variables in (x, y). The full array of nine louvers converges from an inlet $|y|=Y$ to an exit $|y|=Y / A r$, with Ar the inlet to minor flow height ratio. For such classifiers in $(x, y)$ an array of louvers converges from an inlet $|y|=Y$ to an exit $|y|=Y / A_{r}$, with $A_{r}$ the inlet to minor flow height ratio. The geometry is also characterized by $\alpha$, the face angle of the louver array relative to the centerline $\mathrm{x}$ - axis, the louver chord length $\mathrm{c}$, the distance between the louvers $b$, and the angle $\beta$ between a louver and the face of the array. Gas and particles enter through $\mathrm{Y}$ with an axial velocity $\mathrm{V}$ and encounter the louvers inclined at an angle of attack $\alpha+\beta$. Jackson [13] comments that "...each [louver] passes gas from only a thin layer... There is thus a localized change of direction of gas..." and so the axial velocity tends to be constant along the centerline of the classifier, e. $g$. [8]. The major portion of the gas is deflected by the louvers and passes through the distance $b$ between adjacent flat plates, accompanied by the particles with small Stokes number St. A minor portion of the gas and the particles with larger St, affected by both impact with the louvers and aerodynamic forces, pass downstream through $\mathrm{Y} / \mathrm{A}_{\mathrm{r}}$ for collection.

The work of Ushiki et al [2] and Poulton et al [5] suggest that pressure loss is affected by these geometric variables and the properties of the inlet gas flow $\rho, \mu$, and $\mathrm{V}$ while the fractional collection efficiency is also affected by the particle properties $\rho_{p}$ and $D_{p}$. That reasoning, applicable to dilute particle concentrations that do not affect the gas flow, is followed here. Dimensional analysis yields the dependent variables, fractional collection efficiency $\eta$, and pressure loss coefficient $\mathrm{C}_{\mathrm{p}}$, as functions of the independent variables (Re, St, $\left.\alpha, \beta, A_{r}, b / c, K\right)$. The distance between the louvers $b$ is the characteristic length scale in the Stokes number St, and the inlet height $\mathrm{Y}$ is that in the Reynolds number Re. $\mathrm{K}$ is used here as a measure of the roughness of the louver array and is the ratio of the y-projection of the louver pitch, defined by $\mathrm{b} / \sin (\beta)$, to the inlet height $\mathrm{Y}$. The number of louvers in the array is calculated through $\mathrm{K}$ and the other geometric variables. Numerical values of the dimensionless variables for the data in this analysis are summarized in Table I. The Stokes number, St, is used in the correlation of fractional collection efficiency $\eta$ and the Reynolds number, Re, characterizes the hydrodynamic environment affecting $\eta$ and pressure loss $\Delta \mathrm{P}$.

The data is from experiments with a 3 to 10 fold range in the independent variables, so the linear regression of $\eta$ is formulated with these variables written as $\log (\alpha)$, etc. There is evidence of quadratic behavior in $\log (\alpha)$ and $\log (\mathrm{K})$, and so these variables are centered on their respective mean values [23]. The "backward 
elimination procedure" is applied to successively delete independent variables in the linear regression with the smallest ratio of the regression coefficient of that variable to the standard error of the coefficient [21, 22]. 


\section{Results and discussion}

\subsection{Pressure Loss}

The hydrodynamic environment of the louvered inertial classifier is an important influence on fractional collection efficiency. So the correlation should be based on experiments with both hydrodynamic and geometric similitude. From Table I the values of $\alpha, \beta, A_{r}, b / c, K$ and Re provide evidence of such similarity for the experiments of Hiyoshi et al [1], Ushiki et al [2] and Okada, et al [3]. The geometry of all classifier arrays are defined by $\alpha, \beta$, Ar, b/c, and $\mathrm{K}$ and the hydrodynamic environment for each geometry is affected by rather large Re.

Similitude is supported by the pressure loss $\Delta \mathrm{P}$ of [2] and [3] which are in qualitative and quantitative agreement and also aligned with that for other rectilinear classifiers [24 - 25]. This is shown in Figure 2 where $\Delta \mathrm{P}$ tends to be proportional to the square of the inlet velocity, with the ratios $\Delta \mathrm{P} / \mathrm{V}^{2}$ approximately constant, but specific to each geometry, as listed in Table I. This is analogous to the pressure loss coefficient for flow in conduits or the drag coefficient on isolated aerodynamic shapes, which tend to be independent of Reynolds number at high velocities. This data in Figure 2 suggests that the flow regime is

turbulent with the pressure loss $\Delta \mathrm{P} / \mathrm{V}^{2}$ only weakly affected by Reynolds number, Re. This dependence of $\Delta \mathrm{P}$ on $\mathrm{V}$ is observed by [24] for a smaller data base, and as in that reference, $\Delta \mathrm{P}$ is that from the cited literature, often without documentation on type and location of the pressure taps. While [1] doesn't state pressure loss, the inlet velocities $(\mathrm{Re})$ and the geometry $\left(\alpha, \beta, \mathrm{A}_{\mathrm{r}}, \mathrm{b} / \mathrm{c}, \mathrm{K}\right)$ of the classifier are similar to those of [2] with $\mathrm{Ar}=3.5$, and we infer that the gas flow environment in [1] is turbulent. In contrast to the data in Figure 2, $[5,6,25]$ report other $\Delta \mathrm{P}$ and $\mathrm{C}_{\mathrm{p}}$ that exhibit a dependence on Re.

The data in Figure 2 illustrate the influence of the geometric parameters, listed in Table I, with the face angle of the array $\alpha$ being prominent. For Okada et al [3] $\Delta \mathrm{P}$ decreases as $\alpha$ decreases from $10^{\circ}$ to $2^{\circ}$. Similar behavior in $\Delta \mathrm{P}$ is observed for $\mathrm{A}_{\mathrm{r}}=3.5$ of Ushiki et al [2] as $\alpha$ decreases from $8^{\circ}$ to $2^{\circ}$ with a hint of a minimum near $\alpha=4^{\circ}$. It is expected that $\mathrm{K}, \mathrm{A}_{\mathrm{r}}$, and $\mathrm{b} / \mathrm{c}$, will affect $\Delta \mathrm{P}$ as known for fluid flow in conduits. However, the respective influences here are more muted and complex. For example, in the data from [2] with $\mathrm{Ar}=5.5, \mathrm{~K}=0.761$, the pressure loss $\Delta \mathrm{P}$ increases slightly as b/c decreases from 1.25 to 0.75. But for Gee and Cole [25], $\Delta \mathrm{P}$ decreases when $\mathrm{b} / \mathrm{c}$ decreases, suggesting a non-linear influence of $\mathrm{b} / \mathrm{c}$. Also, when $\alpha=4^{\circ}, \Delta \mathrm{P}$ for $\mathrm{A}_{\mathrm{r}}=3.5,5.5$ from [2] and $\mathrm{A}_{\mathrm{r}}=10$ from [3] are approximately aligned and suggest that differences in roughness $\mathrm{K}$, blade gap to chord ratio $\mathrm{b} / \mathrm{c}$, and inlet to exit area ratio $\mathrm{A}_{\mathrm{r}}$ have less affect than $\alpha$. The influence of $\beta$, the angle between a louver and the face of the array, is examined by [3] which concludes that $\Delta \mathrm{P}$ is relatively independent of $\beta$ for $30^{\circ}>\beta>20^{\circ}$. That range is applicable to the data of [2] and [3] in Figure 2.

The pressure loss of El-Zaiat et al [4] is smaller than the others; it is for a classifier geometry very similar to [3], but with a different installation. For [2,3] the major flow, downstream of the louvers, expands to a 
plenum where pressure is measured. However in [4] that downstream pressure is measured in the major flow as it is guided in a channel that is aligned with the louvers. This is a reminder that measured pressure loss is not only affected by the louvers but may include the influence of the plenum, pipe or conduit, in which the classifier is installed. Also, the geometry and orientation of the louvers proximate to the exit $|y|=$ $\mathrm{Y}_{\mathrm{A}}$, together with the conduit can affect the local pressure and the minor flow [6]. 


\subsection{Fractional Collection Efficiency}

The fractional collection efficiency data from Ushiki et al [2] - fly ash, lycopodium, acrylic resin, Okada et al [3] - fly ash, and Hiyoshi et al [1] - fly ash, are correlated to establish $\eta$ in the neighborhood of $\eta=0.5$ for $0.2<\mathrm{St}^{1 / 2}<1.0$. That data in [ $\left.\log \left(\mathrm{St}^{1 / 2}\right), \eta\right]$ is from Figs. 2 and 4 of [2], Fig. 3 of [1], and Fig.15 of [3] as interpreted by [24]. Based on Section 3.1 it is expected that the hydrodynamic regime is turbulent and the flow is only weakly affected by Reynolds number. Consequently it is assumed that Re has no influence on the correlation of $\eta$. That correlation is developed in accordance with Section 2 and is based on 34 data points with the range of independent variables summarized in Table I:

$$
\mathrm{H}=1.186+0.961 \log \sqrt{\mathrm{St}}-2.407[\log (\alpha)-\overline{\log (\alpha)}]^{2}+0.250[\log (\mathrm{K})-\overline{\log (\mathrm{K})}]^{2}-0.431 \log \left(\mathrm{A}_{\mathrm{r}}\right)
$$

Where $\mathrm{H}$ is the conditional mean of the fractional collection efficiency, and the definition of this linear regression, including "t statistic", "p - value" and confidence interval for the coefficients, is provided in Table II. The numerical values of

$\overline{\log (\alpha)}=-1.164, \quad \overline{\log (\mathrm{K})}=-1.235$

correspond respectively to $\alpha=0.0686\left(3.933^{\circ}\right)$ and $\mathrm{K}=0.0582$. $\mathrm{H}$ decreases with the inlet to exit area ratio, $\log \left(\mathrm{A}_{\mathrm{r}}\right)$, is quadratic in the face angle of the blade array, $\log (\alpha)$, and the roughness of that array, $\log (\mathrm{K})$. The linear regression, within the context of the confidence intervals in Table II, exhibits a slope in $\left[\log \left(\mathrm{St}^{1 / 2}\right), \mathrm{H}\right]$ that is close to unity.

Figure 3 shows a comparison of the individual data points for the fractional collection efficiency $\eta$ with the conditional mean $\mathrm{H}$ from Eq. (1) and demonstrates that the linear regression is effective in describing $\eta$ for the range of independent variables in Table I. Eq. (1) is applied selectively to data in the traditional $\left[\log \left(\mathrm{St}^{1 / 2}\right), \eta\right]$ format in Figure 4, where the larger stylized symbols indicate the observations used in the linear regression. The correlation of $\eta$ for $\alpha=4^{\circ}$ and respectively $A_{r}=3.5$ from Ushiki et al [2] and Ar $=10$ from Okada et al [3] establish the bounds of the data. The other Ushiki et al [2] data are within those bounds. Also the correlation of $\mathrm{A}_{\mathrm{r}}=3.5, \alpha=4^{\circ}$ for [2] and the correlation for Hiyoshi et al [1] are approximately aligned because of the similar geometric variables. The quadratic influence of $\alpha$ on Eq. (1) is observed in the data for $\mathrm{A}_{\mathrm{r}}=3.5$ from [2]; at any $\mathrm{St}^{1 / 2}$ the fractional collection efficiency $\eta$ is a maximum near $\alpha=4^{\circ}$ and decreases for $\alpha$ equal to either $2^{\circ}$ or $8^{\circ}$. There is also agreement between the correlation and the data of [2] for $\mathrm{Ar}=5.5, \mathrm{~K}=0.0761$ with no apparent influence of the gap to chord ratio $0.25 \leq \mathrm{b} / \mathrm{c} \leq$ 1.25. The quadratic influence of $\mathrm{K}$ on Eq. (1) is suggested by the data for $\mathrm{Ar}=5.5$, where $\mathrm{K}=0.0254$, $0.1268,0.2029$ tend to yield higher $\eta$, for any $\mathrm{St}^{1 / 2}$, than that for $\mathrm{K}=0.0761$.

While Eq. (1) offers specific guidance on the influence of the independent variables $\left(\mathrm{St}^{1 / 2}, \alpha, \mathrm{A}_{\mathrm{r}}\right.$ and $\left.\mathrm{K}\right)$ upon fractional collection efficiency, other general conclusions are possible. It provides some measure of the respective experimental protocols for measuring fractional collection efficiency in [1 - 3]. Again, the 
fractional collection efficiencies of [1] and [2], for similar geometries and flow conditions, are in agreement for $\mathrm{St}^{1 / 2}<1$, and the correlation integrates the data of all three studies for $.2<\mathrm{St}^{1 / 2}<1$. The correlation also enables a comparison of rectilinear louvered inertial classifiers with other devices. Since the coefficient of $\log \left(\mathrm{St}^{1 / 2}\right)$ in Eq. (1) is approximately unity the louvered classifiers in this study do not offer the sharp cut-off in $\left[\log \left(\mathrm{St}^{1 / 2}\right), \eta\right]$ available from some impactors [19] and cyclone classifiers [15].

The ratio b/c does not appear in the correlation. But b, the distance between the louvers, is the physical length that defines the fluid dynamic time scale in the Stokes number St, and the roughness in the variable $\mathrm{K}$. Also, the angle between the louver and the face of the array $\beta$, does not appear explicitly in Eq. (1), but it too is contained in $\mathrm{K}$.

Again, the independent variables eliminated from or retained in Eq. (1) are assessed as in [22], using the "backward elimination procedure" to establish the statistical significance and also pairs of these variables are tested using scatterplots and a matrix of sample correlations. It can be shown that there is essentially no correlation between those independent variables, except for the subset $\mathrm{Ar}=3.5$ of [2] where $K=K(\alpha)$. In the backward elimination procedure a variable is retained if the "t statistic", which is the ratio of the regression coefficient of that variable to the standard error of the coefficient, is greater than 2. The quadratic term $[\log (\mathrm{K})]_{\mathrm{C}}{ }^{2}$ satisfies this criteria but is close to that limit. It may be appropriate to exclude that independent variable relative to $[\log (\alpha)]_{\mathrm{C}}{ }^{2}$ and thereby simplify the correlation. However it represents the differences in the data of [2] for $\mathrm{Ar}=5.5, \alpha=4^{\circ}$ with $0.2029 \geq \mathrm{K} \geq 0.0254$ and so it is retained for describing the data in Figure 4 and assessing the conceptual designs in Section 3.4. If $[\log (\mathrm{K})]_{\mathrm{C}}{ }^{2}$ is excluded based on the $t$ statistic, the simplified correlation of fractional collection efficiency is:

$$
\mathrm{H}=1.170+0.937 \log \sqrt{\mathrm{St}}-2.187[\log (\alpha)-\overline{\log (\alpha)}]^{2}-0.399 \log \left(\mathrm{A}_{\mathrm{r}}\right)
$$

The coefficients of the retained independent variables in this simplified correlation and the quantitative measures of those coefficients, shown in Table II, are approximately equal to those of the respective variables in Eq. (1). This equation describes $\eta$, albeit slightly limited, through only two geometric variables that define the converging profile of the louver array.

Neither $\beta$, the angle between the louver and the face of the array, nor the inclination of the louver $\gamma=\alpha+\beta$, appears in Eqs. (1) - (2). However there is evidence [3-6,11] that they do affect total mass collection, which is dominated by fractional collection efficiency for $\mathrm{St}^{1 / 2}>1$. This suggests that a broader data base will require $\beta$ or $\gamma$ in a regression analysis of $\eta$ for $S t^{1 / 2}>1$ and, perhaps, a modification of Eqs. (1) - (2) for $\mathrm{St}^{1 / 2}<1$. In part, the absence of either angle in Eqs. (1) - (2) may be explained by the range of experimental variables in [1-3]. For [2] $\gamma=34^{\circ}$ for all experiments and $\beta=\gamma-\alpha$ is not independent of $\alpha$. Conversely, it can be shown that the angle $\gamma$, together with $\alpha$ and $A_{r}$, yields a linear regression for the data of [1-3] that is comparable to Eq. (2), with a term $\log (\gamma)$ added and the magnitude of the coefficient of $\log \left(A_{r}\right)$ reduced. A scatter plot would show a correlation between the independent variables $\log (\gamma)$ and $\log \left(A_{r}\right)$ for the data in $[1$ - 3]. This means that $\log (\gamma)$ and $\log \left(A_{r}\right)$ are [22] "in part...explaining the same variation" of $H$. Since 
$\log (\gamma)$ and $\log \left(\mathrm{A}_{\mathrm{r}}\right)$ are correlated, a regression including $\log (\gamma)$ does not replace Eq. (2), but it does suggest a frame for including $\gamma$ or $\beta$ if a broader data base is available.

It is established practice $[11,25]$ that optimum $\eta$ in louvered classifiers is achieved when the ratio of minor to inlet volume flow (blow down ratio) equals the exit to inlet area ratio, 1/ $\mathrm{A}_{\mathrm{r}}$. For the literature cited herein, that appears to be the case. Hiyoshi et al [1] explicitly describe the experiment accordingly, while Okada et al [3] define a blow down ratio (0.10) and geometric parameters showing $1 / \mathrm{A}_{\mathrm{r}}=0.10$ for $\alpha=4^{\circ}$. Ushiki et al [2] do not quantify blowdown; but both minor and major flows exit to the same plenum pressure and the relatively large $\left(1 / \mathrm{A}_{\mathrm{r}}\right)$ is likely consistent with blowdown. If blow down ratio is measured and different than $\left(1 / \mathrm{A}_{\mathrm{r}}\right)$ then another independent variable is required in Eq. (1). 


\subsection{Other Geometries and Data}

Various designs of louvered inertial classifiers are discussed in the cited literature and comprehensive reviews are presented by $[8,9]$. Unfortunately, most data is either for total mass collection efficiency [3-6, 11] or for fractional collection efficiency [5, 11 - 13] without adequate documentation of the experiment. However data on fractional collection efficiency from two dissimilar geometries [7, 8] provide some comparison in Figure 5 with the simplified correlation Eq. (2) and the data of [3].

Alekseev et al [7] use a rectilinear classifier with "conical louvered elements" comprising two planar louvered surfaces joined at a vertex which converges from inlet to exit. A cross section of each planar louvered surface is analogous to Figure 1 with a face angle, $\alpha=6^{\circ}$ and $b=0.004 \mathrm{~m}$; the classifier blowdown is $10 \%\left(\mathrm{~A}_{\mathrm{r}}=10\right)$. Fractional collection efficiency of dust is converted here into [ $\left.\mathrm{St}^{1 / 2}, \eta\right]$ assuming $\rho_{\mathrm{p}}=2400 \mathrm{~kg} / \mathrm{m}^{3}$ and $\mu=1.79 \times 10^{-5} \mathrm{~kg} /(\mathrm{m}-\mathrm{s})$ and shown in Figure 5. Eq. (2) predicts that the fractional collection efficiency for $\left(\alpha=6^{\circ}, A_{r}=10\right)$ [7] decreases relative to that for $\left(\alpha=4^{\circ}, A_{r}=10\right)$ [3]. While the measurements of [7] are sensitive to $\mathrm{V}$, Eq. (2) appears to represent the influence of $\alpha$ and $\mathrm{A}_{\mathrm{r}}$ on that data for $\mathrm{St}^{1 / 2}<1$. Near $\mathrm{St}^{1 / 2}=1$ there is some scatter in the data of [7] and for $\mathrm{St}^{1 / 2}>1$ the data of [3] and [7] diverge.

Frain [8] investigates an axisymmetric louvered classifier composed of a cone of rings [11]. The cross section of each ring has a blunt aerodynamic shape with an inner convex surface pointed upstream and outer and aft surfaces that are flat; the influence of ring spacing on the fractional collection efficiency is studied. That axial distance, measured from the aft surface of a ring to the nose of a following ring, is used here as $b$. The data of [8] for glass beads with $[b=.01 \mathrm{~m}, \mathrm{~V}=36 \mathrm{~m} / \mathrm{s}]$ and $[\mathrm{b}=.0254 \mathrm{~m}, \mathrm{~V}=40 \mathrm{~m} / \mathrm{s}]$ is converted here into $\left[\mathrm{St}^{1 / 2}, \eta\right]$ assuming $\rho_{\mathrm{p}}=2500 \mathrm{~kg} / \mathrm{m}^{3}$ and $\mu=1.79 \times 10^{-5} \mathrm{~kg} /(\mathrm{m}-\mathrm{s})$ and shown in Figure 5. While there is some divergence of the data in [8] as $\mathrm{St}^{1 / 2}$ approaches unity and evidence of a larger gradient $\mathrm{d} \eta / \mathrm{d}\left[\log \left(\mathrm{St}^{1 / 2}\right)\right]$ than for [3, 7], there is agreement for all the data $[3,7,8]$ near $\eta=0.5$ and $\mathrm{St}_{50}{ }^{1 / 2} \sim$ 0.5 . With respect to the geometries of [8] the angle $\alpha$ and area ratio $A_{r}$ are larger than those in [3, 7].

Also the blunt convex shape of the rings in [8] is a significant departure from the flat plates in [3, 7]. It is expected that louver shape, other than flat plates, will also affect fractional collection efficiency in rectilinear classifiers. For example, folded louvers are used by [3, 25] to improve total mass collection efficiency of particles. Ushiki et al [24] demonstrate that folded louvers lead to higher fractional collection efficiency for liquid droplets in a mist separator. 


\subsection{Conceptual Design of Louvered Classifiers}

Classifier design seeks a geometry and flow environment that enables a 50\% fractional collection efficiency for a particle of diameter $\mathrm{D}_{\mathrm{p} 50}$ with $\mathrm{St}_{50}=\rho_{\mathrm{p}}\left(\mathrm{D}_{\mathrm{p} 50}{ }^{2}\right) \mathrm{VC}\left(\mathrm{T}, \mathrm{P}, \mathrm{D}_{\mathrm{p} 50}\right) / 18 \mathrm{~b} \mu(\mathrm{T})$. When the conditional mean of the fractional collection efficiency $\mathrm{H}=0.5$, the linear regression line in Eq. (1) can be restated in terms of $\mathrm{St}_{50}$.

$0.961 \log \sqrt{\mathrm{St}_{50}}=-0.686+2.407[\log (\alpha)-\overline{\log (\alpha)}]^{2}-0.250[\log (\mathrm{K})-\overline{\log (\mathrm{K})}]^{2}+0.431 \log \left(\mathrm{A}_{\mathrm{r}}\right)$

Within the confidence intervals stated in Table II, Eq. (3) is interpreted here as relating the dependence of $\mathrm{St}_{50}{ }^{1 / 2}$ upon the geometry of the classifier and its influence in the selective classification of a particle of size $\mathrm{D}_{\mathrm{p} 50}$. The value of $\log \left(\mathrm{St}_{50}\right)^{1 / 2}$ and $\log \left(\mathrm{D}_{\mathrm{p} 50}\right)$ is quadratic in $\log (\alpha)$ and $\log (\mathrm{K})$ and increases with $\log \left(\mathrm{A}_{\mathrm{r}}\right)$.

The application of Eq. (3) to the conceptual design of flat plate rectilinear louver classifiers is analogous to design protocols of impactors, e. g. Sioutas et al [18]. Specifically the Stokes number in Eq. (3) is combined with the ideal gas equation of state, conservation of mass for the gas, Hering's [26] conservation of energy equation for adiabatic flow, and the geometric parameters defining the classifier, $\alpha, A_{r}, K$. The slip correction $\mathrm{C}\left(\mathrm{T}, \mathrm{P}, \mathrm{D}_{\mathrm{p}}\right)$ is that of Davies [27], as also used by [15, 18, 28]. A mean free path in the slip correction is from [28], using the kinetic theory of an ideal gas. If the ambient pressure and temperature $\left(\mathrm{P}_{\mathrm{o}}, \mathrm{T}_{\mathrm{o}}\right)$ and inlet mass flow $\rho_{\mathrm{o}} \mathrm{q}_{\mathrm{o}}$ are known, then the operating pressure of the classifier $\mathrm{P}$, and the "cut diameter" $\mathrm{D}_{\mathrm{p} 50}$, specify the height of the classifier inlet $\mathrm{Y}$ and the inlet axial gas velocity V. Geometric and hydrodynamic similitude with the experiments of [1 - 3] is assured if geometric parameters and Re of the conceptual designs are limited to values consistent with those in Table I. Select results are shown in Table III.

Naturally, such predictions reproduce the experiments of [1 - 3]. This is illustrated in the first line of Table III for the Ushiki et al [2] geometry, but with $A_{r}=5$, where $D_{p 50}=6 \mu \mathrm{m}$ can be obtained with an inlet velocity of $\sim 4 \mathrm{~m} / \mathrm{s}$ in a classifier with an inlet height $\sim 5 \mathrm{~cm}$; the inlet Reynolds number is on the order of 15000. If $\mathrm{q}_{\mathrm{o}}=0.22 \mathrm{~m}^{2} / \mathrm{s}$ but $\mathrm{D}_{\mathrm{p} 50}=1 \mu \mathrm{m}$, the second and third lines of the table indicate two different strategies for the operating pressure: either near atmospheric or $0.1 \mathrm{~atm}$. For the former the inlet height is approximately $1 \mathrm{~cm}$ and the inlet velocity $24 \mathrm{~m} / \mathrm{s}$. But when the pressure is reduced to 0.1 atm, the geometry on line 3 is almost the same as the configuration on line 1 , albeit with an inlet velocity of approximately $48 \mathrm{~m} / \mathrm{s}$.

The fourth line in Table III examines a particle $\left(\rho_{\mathrm{p}}, \mathrm{D}_{\mathrm{p} 50}\right)$ and an operating pressure similar to the rectilinear 
impactor of Sioutas et al [18]. However here the volumetric flow rate $\mathrm{q}_{\mathrm{o}}$ is approximately fivefold larger. The inlet velocity, $\mathrm{V}$ and the exit dimension $\mathrm{Y} / \mathrm{A}_{\mathrm{r}}$ are of the same magnitude as the nozzle velocity and height reported by [18], implying that the minor flow in the louvered classifier is comparable to the flow through that impactor. The fifth line of the table examines a limestone particle with P comparable to that for the counter-flow centrifugal classifier in Leschonski [28] and Yamada et al [29], but here $\mathrm{q}_{\mathrm{o}}$ is larger and $\mathrm{D}_{\mathrm{p} 50}$ is smaller, with the inlet velocity approximately equal to the circumferential velocity reported by [28].

Naturally, high gas velocities and small dimensions in Table III require that practical designs for such louvered classifiers achieve a careful control of the hydrodynamic environment as displayed in conventional and virtual impactors [18 - 20]. Also, while sub-atmospheric pressures are used in cyclone classification of fine particles $[15,28,29]$, there is little data for louvered classifiers to support the conceptual designs in Table III. Witman [30] does provide proof-of-concept experiments with a small rectilinear louvered classifier of fixed geometry and $20 \%$ blowdown ratio, analogous to lines 1 and 3 of Table III, but with constant $\mathrm{V}=10 \mathrm{~m} / \mathrm{s}$. Thereby the gas dynamic time scale is fixed and a decrease in operating pressure increases the particle dynamic time scale and St, as in [31]. Total mass collection efficiency, using glass powder with a Coulter LS230 volume average $D_{p}=3.5 \mu \mathrm{m}$, increases from $20 \%$ to $80 \%$ as the operating pressure $\mathrm{P}$ decreases from 180 to 1.8 Torr. CFD simulation by [32] agrees with the total mass collection data, and predicts a fractional collection efficiency with $\mathrm{D}_{\mathrm{p} 50}=0.6 \mu \mathrm{m}$ at 0.76 Torr that is consistent with Eq.(3), albeit applied at a Reynolds number far below that of the data used here. Such agreement encourages the speculation that Eqs. (1) - (3) might be extrapolated to sub-atmospheric pressures. 


\section{Summary and conclusions}

The correlation of fractional collection efficiency $\eta$ in Eq (1) provides a good description of the data as illustrated in Figure 4. It is based on measurements of Hiyoshi, et al [1], Ushiki, et al [2], and Okada, et al [3] for rectilinear classifiers with flat plate louvers, in turbulent flow where $\eta$ is independent of Reynolds number Re. Particle Stokes number St and non-dimensional variables, defining the classifier geometry, influence Eq. (1) and enable an interpretation of the data.

Both the face angle of the louver array $\alpha$ and the inlet to minor flow area ratio $A_{r}$ are significant in the correlation, while the roughness of the louver array $\mathrm{K}$ is less so. Neither the louver gap to chord ratio b/c nor the angle between the louver and the face of the array $\beta$ affect the correlation. Eq. (1) shows that for a Stokes number $0.2<\mathrm{St}^{1 / 2}<1.0$, the fractional collection efficiency near $\eta=0.5$ increases with $\log \left(\mathrm{St}^{1 / 2}\right)$, decreases with area ratio $3.29 \leq A_{\mathrm{r}} \leq 10$, is maximum at a face angle $\alpha \sim 4^{\circ}\left(2^{\circ} \leq \alpha \leq 8^{\circ}\right)$ and is minimum at a roughness $\mathrm{K} \sim 0.06(0.0254 \leq \mathrm{K} \leq 0.2029)$.

Design of rectilinear louvered classifiers can be based on Eq. (3) which provides a semi-empirical prediction of $\mathrm{St}_{50}{ }^{1 / 2}$ to classify a particle of diameter $\mathrm{D}_{\mathrm{p} 50}$. Table III illustrates conceptual designs of such classifiers including the application to submicron particles where operating pressures and gas velocities to achieve classification are comparable to the impactor of Sioutas et al [18] and the cyclone classifier of Yamada et al [29].

\section{Acknowledgements}

This work was partially supported by the U.S. National Science Foundation under grant CT S-018204 to the University of Massachusetts. Earlier conversations with Dr. K. Annen of Aerodyne Research Inc. have informed the discussion of conceptual designs in the present study. 


\section{References}

[1] Hiyoshi, K., Fujiwara, M. and Okada, K. (1988) Kagaku Kogaku Ronbunshu, 14 (2) 167-172.

[2] Ushiki, K., Sawada, H. and Iinoya, K. (1979) Kagaku Kogaku Ronbunshu, 5 (4) 424-428.

[3] Okada, S., Tsuboi, N., Sasaki, A. and Tsutsui, T. (1970) Hitachi Hyoron, 52 (10) 1-6.

[4] El-Zaiat, R.E.,El-Shoboksky, M.S. and Abdul Jabbar, Z.S. (1992) Aerosol Sci. Technol. (16) 21-42.

[5] Poulton, P., Cole, B.N. and Mobbs, F.B. (1981) "An experimental and numerical investigation of louvered inertia air filter performance", Proc. Conf. Gas Born Particles, Oxford, I.Mech.E, June, 161-170.

[6] Musgrove, G.O., Thole, K.A., Grover, G. and Barker, J. (2013) ASME J. Eng. Gas Turb. \& Power, 135 (1).

[7] Alekseev, A.V., Mikhailov, E.I. and Sokolov, N.V. (1972) Teploenergetika 19 (7) 26-29.

[8] Frain, M.J. (2000) "Study of an inertial impingement-type gas/particle separator", MSME Thesis, U. Massachusetts at Amherst.

[9] Han, J. (1996) "Performance of the aerodynamic particle separator: experiments and computational analysis", PhD Thesis, U. Wisconsin.

[10] Bakharev, I. "Device for separating multi-component fluids" U.S. Patent 5,221,305, June 22, 1993.

[11] Zverev, N.I. (1946) Engineers Digest (3) 11, 557 - 559.

[12] Yokomichi, Y., Morisaki, H. and Yoshida, H. "Method of reducing unburned coal in coal ash", Japan Patent Application JP 08266830, October 15, 1996.

[13] Jackson, R. (1963) Mechanical Equipment for Removing Grit and dust from Gases, BCURA, Leatherhead.

[14] Filippone, A., and Bojdo, N. (2010) Prog. Aerospace Sci. 46, 224 - 245.

[15] Hsiao, T-C., Chen, D-R., Li, L., Greenberg, P. and Street, K.W. (2010) Aerosol Sci. Technol. (44) 253-261. 
[16] Knowlton, T.M. (2003) "Cyclone separators", Handbook of Fluidization and Fluid Particle Systems, Ed. W-C Yang, Taylor \& Francis Group.

[17] Hoffman, A.C. and Stein, L.E. (2002) Gas Cyclones and Swirl Tubes, Springer

[18] Sioutas, C., Ferguson, S.T., Wolfson, J.M., Ozkaynak, H. and Koutrakis, P. (1997) J. Aerosol Sci., 28

(6) $1015-1028$.

[19] Chen, B.T., and Yeh, H.C. (1987) J. Aerosol Sci., 18 (2) 203-214.

[20] Marple, V.A, and Chien, C.M. (1980) Environ. Sci. Technol. 14, 976-984.

[21] Chatterjee, S., and Price, B. (1977) Regression Analysis by Example, John Wiley.

[22] Weisberg, S. (2014) Applied Linear Regression, $4^{\text {th }}$ Edition, John Wiley.

[23] PennState U., Stat 501 Regression Methods, https://onlinecourses.science.psu.edu/stat501/node/349

[24] Ushiki, K. Kato, H., Takahashi, S., and Iinoya, K. (1981) Intl Chem. Eng., 21 (1) 57-65.

[25] Gee, D.B. and Cole, B.N. (1969) "A study of the performance of inertia air filters", Fluid Mechanics and Measurements in Two Phase Flow Systems, Proc. I. Mech. E, 1969-1970, 184 (3C) 166-174.

[26] Hering, S.V. (1987) Aerosol Sci. Technol. 7, 257-274.

[27] Davies, C.N. (1945) Proc. Physical Soc. London, 57, Part 4 (322) 259-270.

[28] Leschonski, K. (1996) "Classification of particles in the sub-micron range in an impeller wheel air classifier", KONA Powder and Particle J., 14, 52-61.

[29] Yamada, Y., Doi, S. and Iinoya, K. (1987) "Classification characteristics under low ambient pressure", Proc. $12^{\text {th }}$ Annual Powder \& Bulk Solids Conf., May, 215-220.

[30] Witman, A. R. (2005) "Study of a sub-atmospheric impact separator for the collection and classification of sub-micron particles", MSME Thesis, U. Massachusetts at Amherst.

[31] Blake, T.R., and Jakus, K. "Low pressure impact separator for separation, classification and collection of ultra-fine particles” U.S. Patent 7,951,217, May 31, 2011.

[32] Blake, T.R., Schmidt, D., Samel, M., Jakus, K. and Witman, A.R. (2010) "Classification of micron and sub-micron particles with a louver type inertial separator operating at sub-atmospheric pressure”, 317 , Proceedings of World Congress on Particle Technology WCPT 6, Nuremberg, ISBN 9783000305702. 


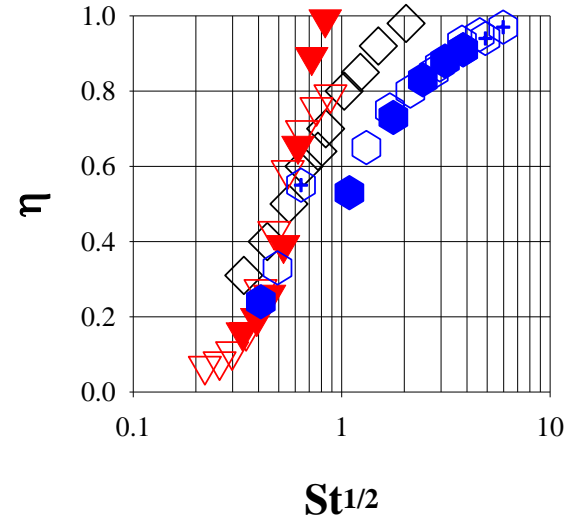

St1/2 
Table I Non-dimensional variables for literature data on $\Delta \mathrm{P}$ and $\eta$, and used in the correlation of $\eta$. Re is estimated from $\mathrm{V}$ and $\mathrm{Y}$ in each reference using the assumption of $\mathrm{T}=288[\mathrm{~K}], \mathrm{P}=1[\mathrm{~atm}]$ for inlet air. $\mathrm{St}^{1 / 2}$ is obtained from Figs. 2 and 4 of [2], Fig 3 of [1], and the Ushiki et al [24] interpretation of Fig 15 of [3]. The angle $\beta$ is not listed; but for [2] $\gamma=34^{\circ}$ and for [1] $\gamma=30^{\circ}$, with $\beta=\gamma-\alpha$. For [3] $\beta=20^{\circ}$. Note that $\alpha$ and $\beta$ are stated here in degrees, but are applied in the correlation as radians.

\begin{tabular}{|l|l|l|l|l|l|l|}
\hline & $\mathbf{R e}$ & $\boldsymbol{\alpha}[\mathbf{o}]$ & $\mathbf{A r}$ & $\mathbf{b} / \mathbf{c}$ & $\mathbf{K}$ & $\Delta \mathbf{P} / \mathbf{V}^{\mathbf{2}}(*)$ \\
\hline Ushiki et al [2] & $4341-24117$ & 2 & 3.5 & 0.375 & 0.0282 & $0.13-0.14$ \\
\cline { 2 - 7 } & $3618-20499$ & 4 & 3.5 & 0.375 & 0.0598 & 0.13 \\
\cline { 2 - 7 } & $4823-16882$ & 8 & 3.5 & 0.375 & 0.1361 & $0.18-0.19$ \\
\cline { 2 - 7 } & $15538-36761$ & 4 & 5.5 & $0.75-1.25$ & $0.0761-0.1268$ & $0.11-0.15$ \\
\hline \multirow{5}{*}{ Okada et al [3] } & $29629-89544$ & 2 & 10 & 0.228 & 0.0162 & $0.10-0.11$ \\
\cline { 2 - 7 } & $18831-92850$ & 4 & 10 & 0.228 & 0.0324 & $0.12-0.14$ \\
\cline { 2 - 7 } & $13587-53897$ & 8 & 10 & 0.228 & 0.0807 & $0.24-0.29$ \\
\hline Hiyoshi et al [1] & $6891-20672$ & 3.3 & 3.29 & 0.2 & 0.0572 & \\
\hline
\end{tabular}

(*) $\left[\mathrm{mmH}_{2} \mathrm{O} /(\mathrm{m} / \mathrm{s})^{2}\right]$

\begin{tabular}{|l|l|l|l|l|l|l|}
\hline & $(\mathbf{S t})^{\mathbf{1} / 2}$ & $\boldsymbol{\alpha}[\mathbf{o}]$ & $\mathbf{A r}$ & $\mathbf{b} / \mathbf{c}$ & $\mathbf{K}$ & $\eta$ \\
\hline \multirow{4}{*}{ Ushiki et al [2] } & $0.23-0.4$ & 2 & 3.5 & 0.375 & 0.0282 & $0.12-0.35$ \\
\cline { 2 - 7 } & $0.21-0.65$ & 4 & 3.5 & 0.375 & 0.0598 & $0.26-0.81$ \\
\cline { 2 - 7 } & $0.47-1.2$ & 8 & 3.5 & 0.375 & 0.1361 & $0.51-0.82$ \\
\cline { 2 - 7 } & $0.25-0.7$ & 4 & 5.5 & $0.25-2.0$ & $0.0254-0.2029$ & $0.30-0.80$ \\
\hline Okada et al [3] & $0.34-1.03$ & 4 & 10 & 0.342 & 0.0324 & $0.31-0.80$ \\
\hline Hiyoshi et al [1] & $0.70-1.0$ & 3.3 & 3.29 & 0.2 & 0.0572 & $0.82-0.90$ \\
\hline
\end{tabular}


Table II Regression results, based on EXCEL, for correlation of $\eta$ in Eq. (1), and simplified correlation in Eq. (2), neglecting $\left\{[\log (\mathrm{K})]_{\mathrm{C}}\right\}^{2}$

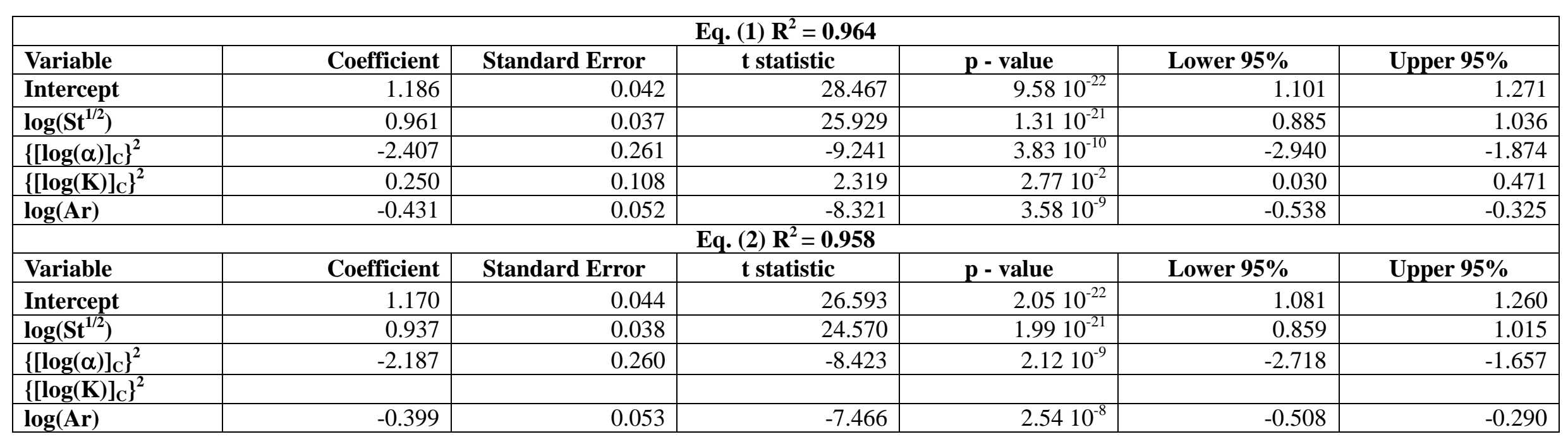


Table III Conceptual design of flat plate louvered rectilinear classifiers based on Eq. (3) using $\alpha=4^{\circ}, \beta=30^{\circ}, A_{r}=5, K=.025$ and $\left(P_{o}, T_{o}\right)=(1$ atm, $293 \mathrm{~K})$

\begin{tabular}{|l|l|l|l|l|l|l|}
\hline $\mathbf{q}_{\mathbf{o}}\left[\mathbf{m}^{2} / \mathbf{s}\right]$ & $\mathbf{D}_{\mathbf{P 5 0}}[\boldsymbol{\mu m}]$ & $\rho_{\mathbf{p}}\left[\mathbf{k g} / \mathbf{m}^{3}\right]$ & $\mathbf{P}[\mathbf{a t m}]$ & $\mathbf{V}[\mathbf{m} / \mathbf{s}]$ & $\mathbf{Y}[\mathbf{m}]$ & $\mathbf{R e}$ \\
\hline 0.22 & 6 & 2500 & 0.99 & 4.28 & 0.052 & 14930 \\
\hline 0.22 & 1 & 2500 & 0.98 & 24.18 & 0.0093 & 14940 \\
\hline 0.22 & 1 & 2500 & 0.10 & 48.17 & 0.045 & 14970 \\
\hline 0.15 & 0.1 & 1047 & 0.70 & 196.29 & 0.001 & 10690 \\
\hline 0.10 & 0.1 & 2710 & 0.10 & 111.30 & 0.0088 & 6891 \\
\hline
\end{tabular}




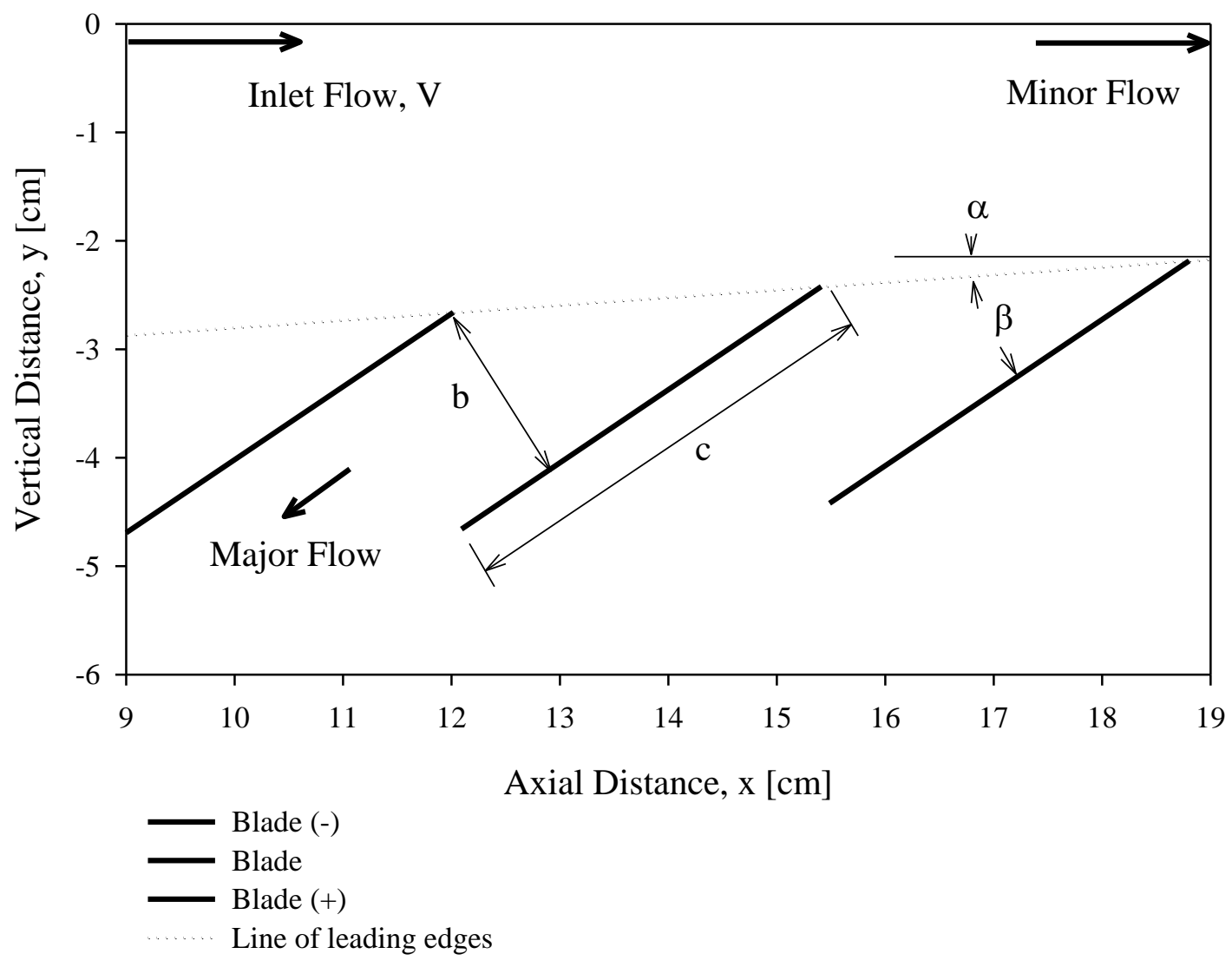

Figure 1. Schematic of a rectilinear flat plate louvered classifier is based on 3 of 9 louvers opposite a flat wall $\mathrm{y}=0$ for the apparatus of [2] with $\mathrm{A}_{\mathrm{r}}=3.5, \alpha=4^{\mathrm{o}}, \mathrm{c}=0.04 \mathrm{~m}, \mathrm{~b}=0.015 \mathrm{~m}$ and $\beta=30^{\circ}$. Gas and particles enter from the left through $|\mathrm{y}|=\mathrm{Y}=0.035 \mathrm{~m}$. The louvers deflect a major portion of the gas and particles with small St, while a minor portion of the gas and particles with larger St pass to the right through an exit $|\mathrm{y}|=\mathrm{Y} / \mathrm{A}_{\mathrm{r}}=0.01 \mathrm{~m}$ 


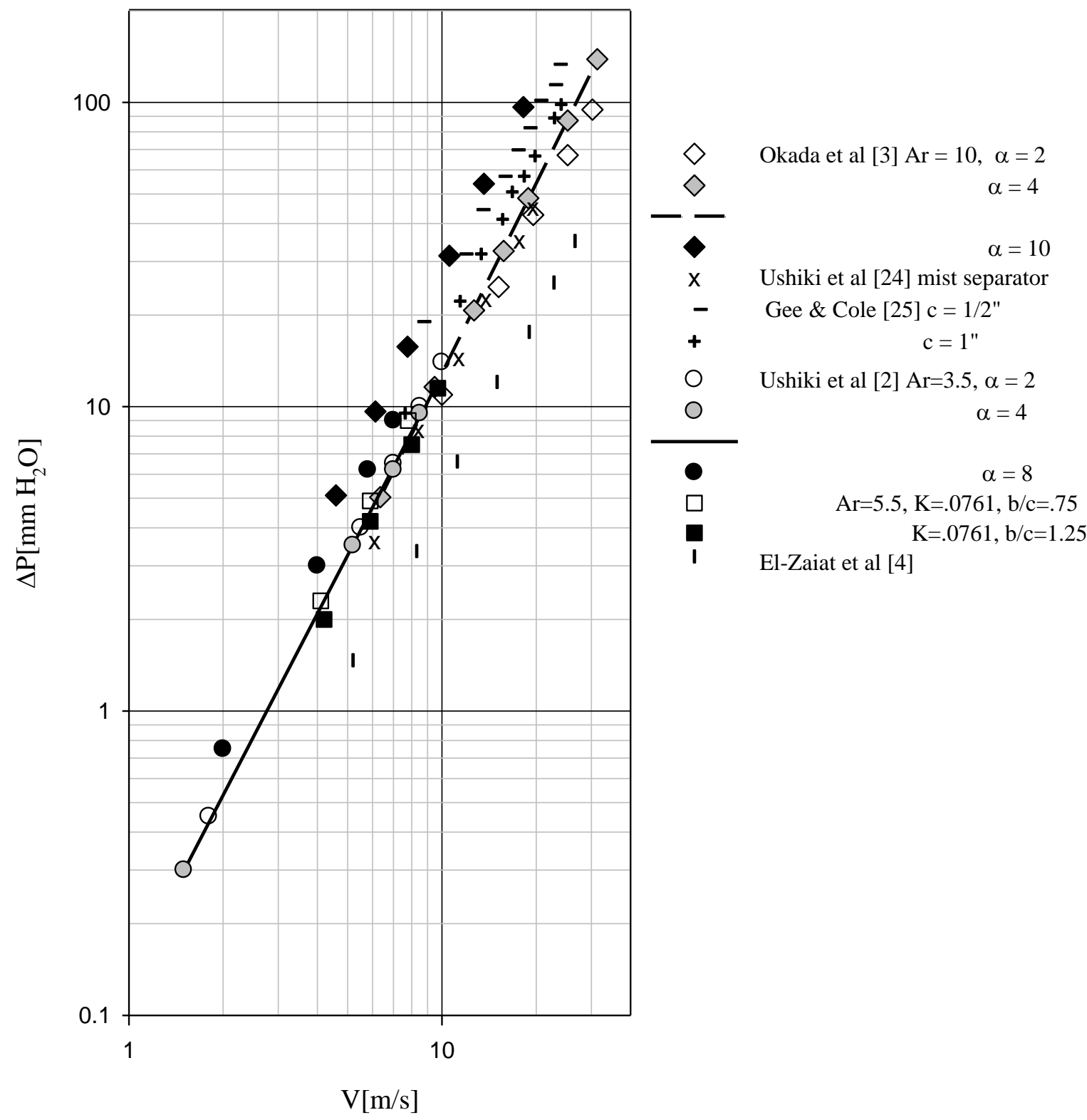

Figure 2. Pressure loss $\Delta \mathrm{P}$ in louvered classifiers tends to be proportional to the square of velocity $\mathrm{V}$, as shown by the data and select straight line fit of that data in $(\mathrm{V}, \Delta \mathrm{P})$. 


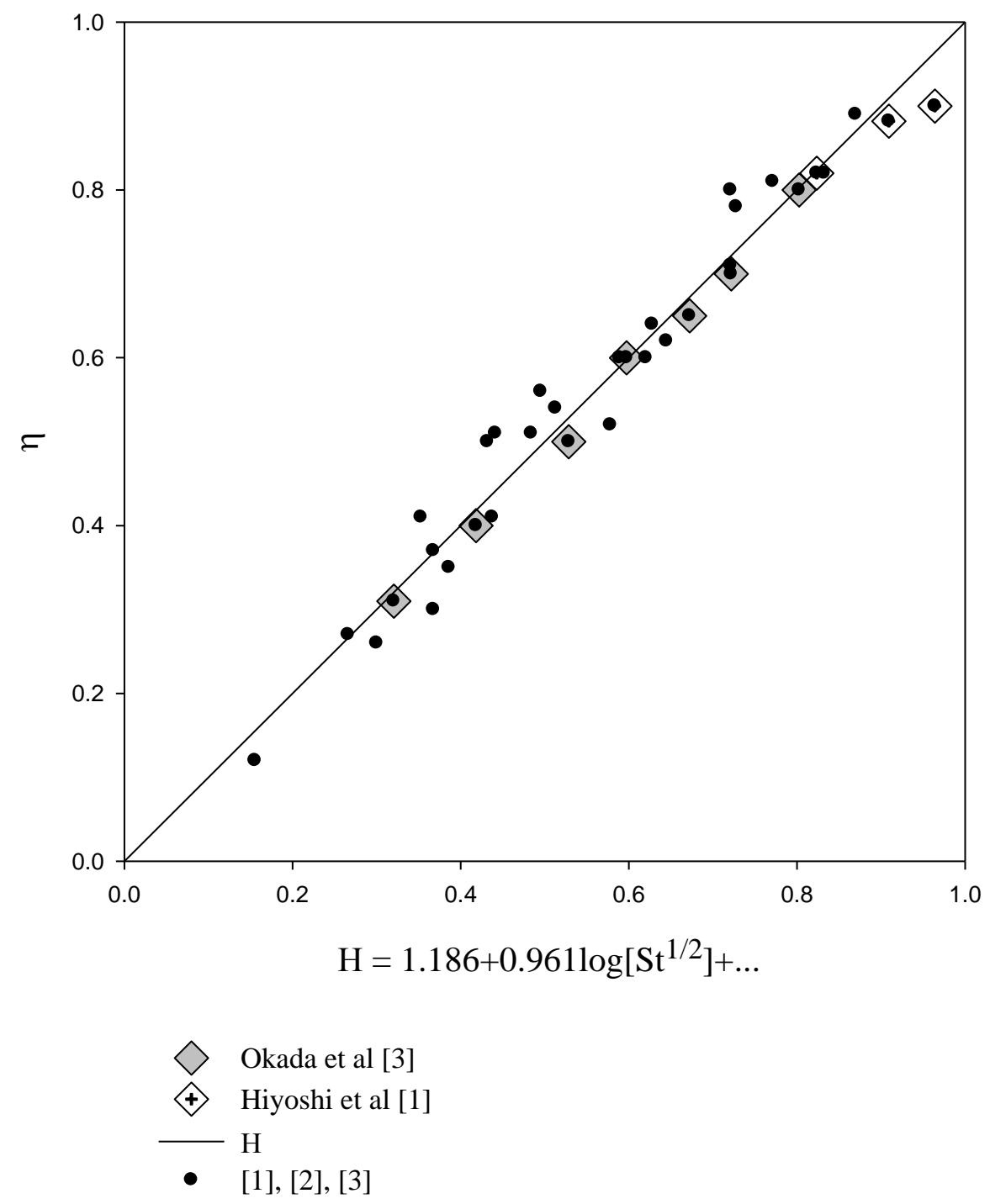

Figure 3 Correlation of $\eta$ in Eq. (1) is compared with data of Ushiki et al [2], Okada et al [3] and Hiyoshi et al [1], where the latter are highlighted. 


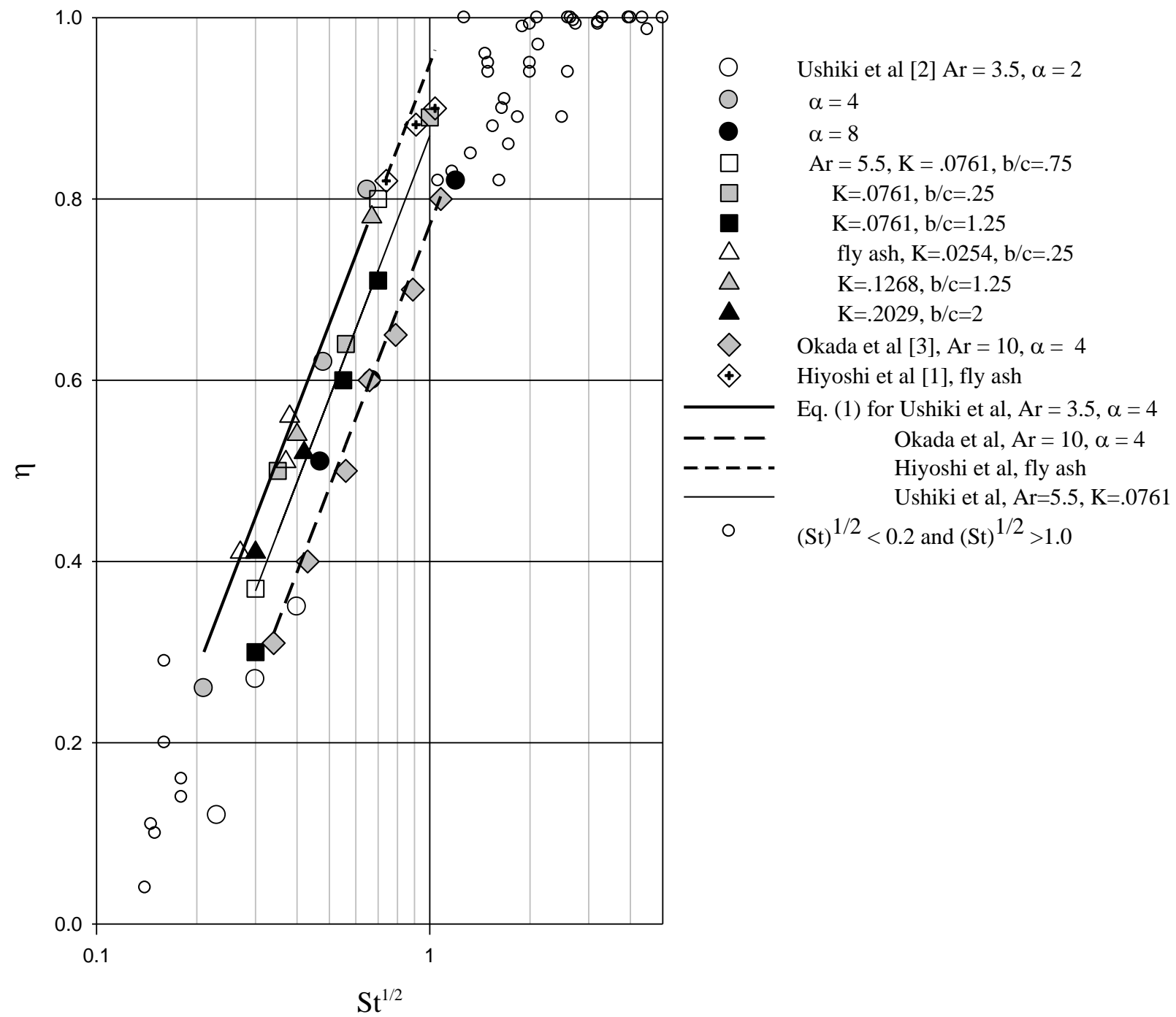

Figure 4 Data on fractional collection efficiency that are used in the correlation are shown as larger stylized symbols. Select data are compared with Eq. (1) and display the influences of $\mathrm{St}^{1 / 2}, \alpha, \mathrm{A}_{\mathrm{r}}$, and $\mathrm{K}$. 


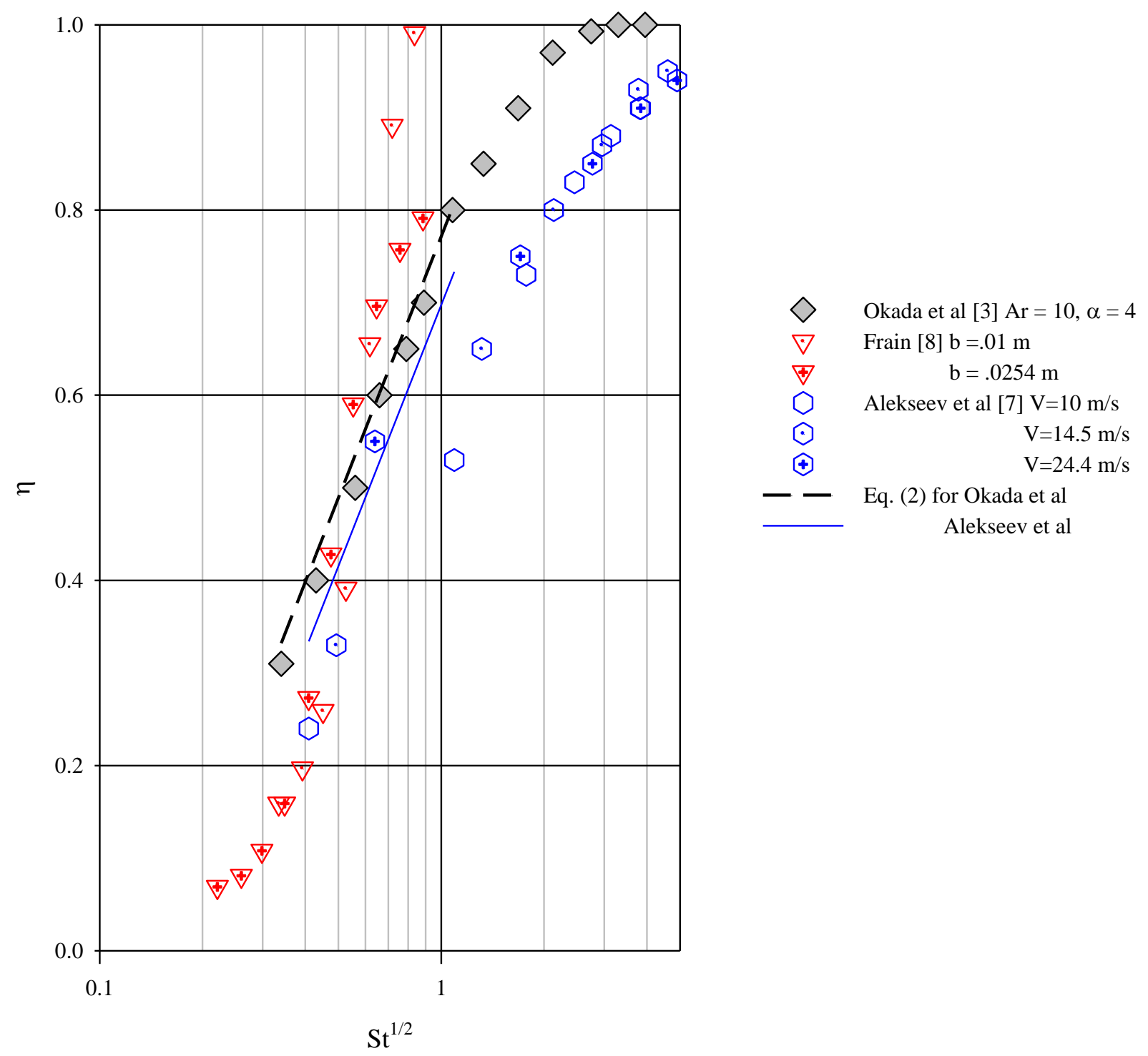

Figure 5 Eq. (2) is compared with Okada et al [3] data and that from the rectilinear classifier of Alekseev et al [7]. Also shown is data from the cylindrical classifier studied by Frain [8]. 